\title{
Complementary feeding in developing countries: factors affecting energy intake
}

\author{
BY KENNETH H. BROWN
}

Program in International Nutrition, Department of Nutrition, University of California, Davis, Davis, CA 95616, USA

The period of complementary feeding refers to the stage of life when foods and/or liquid milks are fed to infants and young children in addition to breast milk; non-breast-milk food items consumed at this time are defined as complementary foods. Complementary foods may be either prepared specially for the young child, both to meet age-related nutritional needs and to mitigate immaturity in chewing and swallowing, or they may be selected from the same foods consumed by the remainder of the family. Depending on the nature of complementary foods, and their nutritional content, hygienic characteristics, and age of introduction, they may be either beneficial or harmful for the young child in particular circumstances.

The optimal age for introduction of complementary foods has been somewhat controversial. Until recently, most international agencies and national and regional paediatric societies have suggested that they should be started during the period from 4 to 6 months of age. However, recent evidence suggests that children who are exclusively breast-fed by reasonably-well-nourished mothers may not benefit from these foods before 6 months (Cohen et al. 1994). Because the introduction of these foods carries an elevated risk of diarrhoea and other infections (Brown et al. 1989; Popkin et al. 1990; De Zoysa et al. 1991), it is not advisable to initiate them before the period of demonstrable nutritional benefit. The World Health Assembly in 1994 urged member states to 'promote sound infant nutrition by fostering appropriate complementary feeding practices from the age of about six months'.

The period of complementary feeding is of particular concern in low-income countries because it is often accompanied by considerable growth faltering with respect to international reference data (Waterlow, 1988; Allen, 1994). The possible reasons for poor growth include low food intake; inadequate content, balance or bio-utilization of specific nutrients; and high rates of infections. The present paper will focus on some of the factors that influence food intake in these settings.

\section{ENERGY INTAKE BY YOUNG CHILDREN IN DEVELOPING COUNTRIES}

There is surprisingly little reliable, quantitative information on energy intakes by young children during the period of complementary feeding. One reason for this is the difficulty in measuring consumption of breast milk and other foods under field conditions. We and others have attempted to collect this type of information (Mata et al. 1977; Van Steenbergen et al. 1980, 1991; Brown et al. 1982; Creed de Kanashiro et al. 1990; Dickin et al. 1990; Drewett et al. 1993), but with few exceptions either the estimation of breast milk consumption was extrapolated from $12 \mathrm{~h}$ measurements, leading to some uncertainty in the results, or the studies were completed only in fully-weaned children. Nevertheless, there is general agreement that the level of energy intake by children from 6 to 24 months of age is substantially less than the Food and Agriculture Organization/World Health 


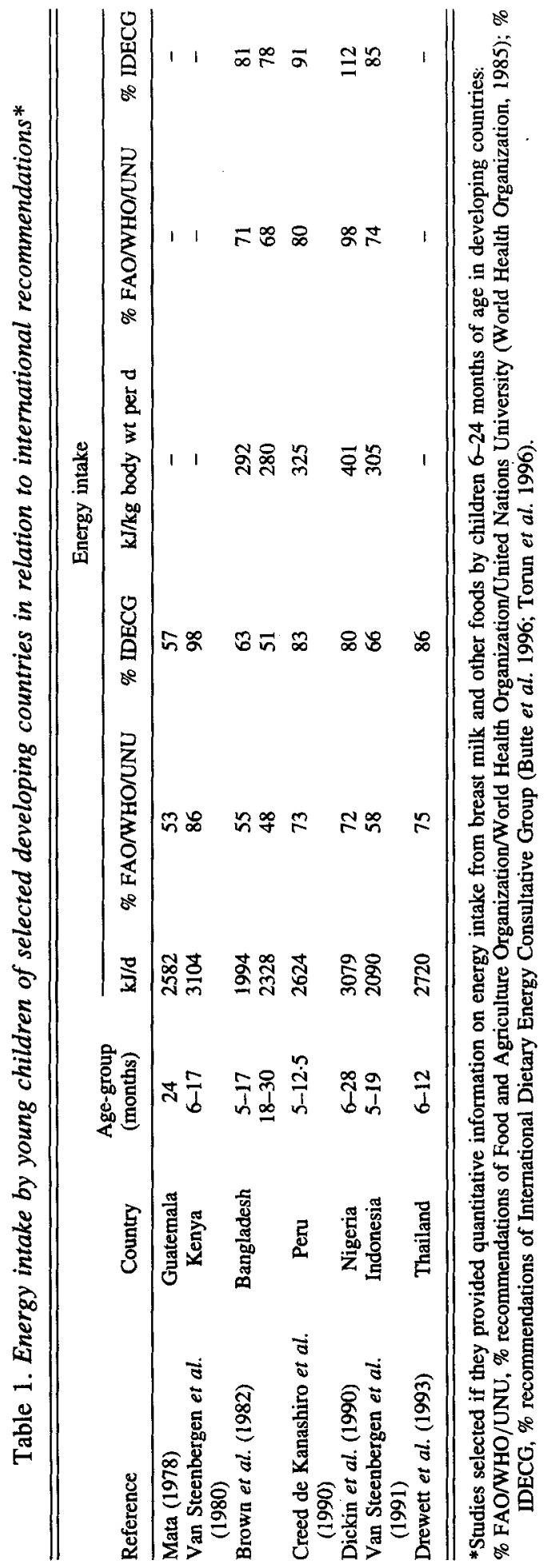


Organization/United Nations University (FAO/WHO/UNU; World Health Organization, 1985) recommendations (Table 1).

The apparent shortfall in energy intake by young children in developing countries may have several explanations. First, it is possible that the FAO/WHO/UNU (World Health Organization, 1985) recommendations overestimate children's energy needs. There is some evidence in support of this possibility, and recent deliberations sponsored by the International Dietary Energy Consultative Group (IDECG) indicate that the FAO/WHO/ UNU (World Health Organization, 1985) guidelines for total daily energy intake exceed energy needs as calculated from the sum of observed energy expenditure and estimated growth requirements by approximately 7-14\% (Butte et al. 1996; Torun et al. 1996). Nevertheless, when we recalculated the observed energy intakes in relation to the revised IDECG guidelines, there was still a shortfall in the observed energy consumption by children in developing countries (Table 1).

A second possible explanation is the fact that children in developing countries are smaller than their counterparts in Europe and North America, both because of higher rates of low birth weight and the aforementioned postnatal growth faltering, so their energy requirements are correspondingly less. Even so, energy intakes per $\mathrm{kg}$ body weight tend to be less among children in low-income countries than the intakes recommended per unit body weight by the international advisory groups (Table 1). Thus, from the limited available data, it seems that, in general, children in developing countries do consume less energy than desirable during the period of complementary feeding.

\section{POSSIBLE EXPLANATIONS FOR LOW ENERGY INTAKE}

There are several possible factors responsible for the low energy intakes observed among young children in developing countries. These can be categorized as: (1) intrinsic, or childrelated, factors; (2) dietary factors; and (3) caregiver behaviours. Intrinsic factors include both genetic variability in energy requirements and altered physiological status, such as may be imposed by illness. Dietary factors include the energy density of the complementary foods, the macro- and micronutrient contents of these foods, their variety, and their organoleptic characteristics, such as taste, aroma, viscosity, etc. Caregiver behaviours include the volume and frequency of feeding, the amount of time devoted to child feeding and the level of supervision and encouragement that are provided. The following sections of the paper will examine primarily some of the intrinsic and dietary factors that influence energy intake. Caregiver behaviours have been reviewed by others previously (Dettwyler, 1989; Bentley et al. 1995; Engle \& Ricciuti, 1995) and will not be dealt with extensively.

\section{Effects of illness on energy intake}

The effects of illness on dietary intakes by children in low-income countries have been studied with a number of different research designs, including clinical studies of hospitalized children (Hoyle et al. 1980; Sarker et al. 1982; Molla et al. 1983), communitybased studies of single episodes of illness (Dickin et al. 1990; Marquis et al. 1993), and community studies in which longitudinal dietary observations or reported anorexia were linked post hoc to morbidity surveillance data (Martorell et al. 1980; Brown et al. 1985, $1990,1995 a$ ). The quantitative results of each of these types of studies are quite variable. Nevertheless, most have found some reduction of intake during illness (Table 2). Clinical studies of children hospitalized for diarrhoea have generally reported a greater reduction in 
Table 2. Impact of diarrhoea on energy intake by young children

\begin{tabular}{llcc}
\hline \hline Study site & \multicolumn{1}{c}{ Reference } & Country & $\begin{array}{c}\text { Percentage reduction in energy } \\
\text { intake during diarrhoea }\end{array}$ \\
\hline Hospital & Hoyle et al. $(1980)$ & Bangladesh & 42 \\
& Molla et al. $(1983)$ & Bangladesh & 37 \\
Community & Bangladesh & 32 \\
& Sarker et al. $(1982)$ & Guatemala & 20 \\
& Martorell et al. (1980) & Bangladesh & 3 \\
& Brown et al. $(1985)$ & Peru & 0 for breast milk \\
& Brown et al. $(1990)$ & Nigeria & 23 for other foods \\
& Dickin et al. al (1990) & Peru & 11 \\
& Marquis et al. $(1993)$ & 25 \\
\hline
\end{tabular}

energy intake during illness than community-based studies. This may be because the illnesses encountered in hospitalized children were more severe or because the highdensity hospital diets that were provided after recovery exaggerated the apparent effects of illness.

Even among the community-based studies there has been considerable variability in the magnitude of the impact of illness. For example, two reports from Guatemala, which included only children who were completely weaned from the breast, noted an average 15$20 \%$ reduction in energy consumption during common illnesses (Mata et al. 1977; Martorell et al. 1980). By contrast, breast-feeding infants and young children in both Bangladesh and Peru, who received about half their energy intake from breast milk, had substantially smaller illness-related decrements in energy intakes (Brown et al. 1985, 1990), possibly because of a protective effect of breast-feeding. Indeed, in the Peru study when energy intakes from breast milk and other foods were examined separately, only the intakes from non-breast-milk sources declined during illness. Thus, part of the difference in the results of previous studies may be explained by the proportions of the children's energy intakes that were derived from breast milk, with greater decrements in intake appreciable when smaller amounts of breast milk were consumed.

With the exception of the previously mentioned study of the effect of breast-feeding on illness-related reductions in energy intake, most previous studies have not examined the possibility that the relationship between illness and energy consumption may be modified by the nature of the diet. Marquis et al. (1993) explored whether a reduction in dietary viscosity would enhance the level of energy intake during illness. In a community-based study in Peru they compared intakes by groups of children who received either an amylase (EC 3.2.1.1)-treated low-viscosity, potato-based diet or an untreated, higher-viscosity mashed-potato diet during and after diarrhoea. Although both groups had lower intakes during illness than following recovery, there was no apparent benefit of the reduced viscosity diet at any stage of illness.

The role of disease severity on energy intake has been examined in two studies. Brown et al. (1995a) examined factors associated with caregivers' reports of poor child appetite during longitudinal observations in Peru. Initial exploration of the relationship between reported anorexia and quantitative studies of energy intake indicated that the caregivers' reports of low child appetite were associated with a $12-15 \%$ reduction in energy intake, depending on age. Reported anorexia was most commonly associated with diarrhoea and respiratory illness. When the illness syndromes were accompanied by fever the likelihood 
of anorexia was considerably greater than when fever was not present. Diarrhoeaassociated anorexia was also more likely to occur when the episode was associated with a higher number of daily bowel movements and during episodes of dysentery and rotavirus infections.

In a descriptive epidemiological study of risk factors for poor appetite among young children hospitalized for diarrhoea, Brown \& Perez (1992) reported that low serum bicarbonate and elevated urinary specific gravity at the time of admission were the two characteristics that independently identified children with low food intakes during the first day of hospitalization. Thus, they proposed that the appropriate therapeutic intervention to reduce diarrhoea-related anorexia is to provide adequate rehydration therapy to prevent dehydration and acidosis.

\section{DIETARY FACTORS AFFECTING YOUNG CHILDREN'S INTAKES}

A number of dietary factors may independently influence children's energy consumption. With collaborators at the Nutrition Research Institute in Lima, Peru we have been carrying out a series of clinical studies to examine selected aspects of the diet that may affect intake. Results of these studies will be described in the following section.

\section{Energy density and frequency of feeding}

To develop estimates of the minimally-adequate energy density of complementary foods, the frequency of feeding must be considered simultaneously. If meals are provided many times during the day, energy needs can be satisfied with lower energy density and vice versa. Thus, both these issues are treated together in this section.

We have recently completed clinical studies of the effects of different frequencies of feeding and composition of meals on total daily energy intakes by fully weaned, recovering malnourished children (Brown et al. 1995b). The ultimate objectives of these studies were to develop specific feeding recommendations concerning the content and sources of dietary energy needed to assure adequate intake. These studies benefited from the high degree of control of feeding practices and food composition that was possible in the clinical setting, but the results must be interpreted with caution due to the nature of the study subjects, all of whom were recovering from recent episodes of severe or moderately-severe proteinenergy malnutrition, and the fact that they were no longer receiving any breast milk. Thus, it is conceivable that these results may not be fully generalizable to non-malnourished, breast-feeding children.

The studies examined the effects on energy intake of providing three different meal frequencies and varied energy densities of semi-solid mixed diets composed of rice, milk, sugar, vegetable oil, and supplemental vitamins and minerals. Colouring, thickening, and flavouring agents were added to the diets so that they were generally indistinguishable in taste and appearance. The preparations were fed ad libitum three, four or five times daily to eighteen children from 6 to 18 months of age whose total daily amounts of food and energy consumption were measured by weighing the feeding bowls before and after each meal.

Controlling for the level of energy density, the total daily amount consumed was approximately $16 \%$ more when the number of meals was increased from three to four daily and $7 \%$ more when the feeding frequency rose from four to five meals daily. The proportionately greater increase in intake with the change from three to four meals daily $v$. the change from four to five meals daily was statistically significant. Therefore, there may be diminishing returns with still further increases in meal frequency. Importantly, 
approximately $15-20 \mathrm{~min}$ were required per meal before the children reached satiety, regardless of the meal frequency. Thus, there was an obvious trade-off between meal frequency and the total amount of feeding time required when additional meals were provided. This time cost may be a severe constraint to greater meal frequency, especially when caregivers have multiple competing responsibilities, including other child-care tasks, as is common in developing countries. The total amount of time required to feed the children each day was related only to the number of meals served, and not to energy density.

These same studies examined the effects of varied energy densities on the children's total daily energy intake (Brown et al. 1995b). Diets of four different densities (1.7, 2.9, 4.2 or $6.3 \mathrm{~kJ} / \mathrm{g}$ ) were provided in random sequence during each of the dietary periods when three, four or five meals were offered daily. The mean amounts of the diet consumed $(\mathrm{g} / \mathrm{kg}$ per d) were significantly less with successively greater energy density of the diet. However, the total daily energy intakes $(\mathrm{kJ} / \mathrm{kg}$ per $\mathrm{d})$ increased significantly with the more concentrated diets. Surprisingly, there was no clear evidence of a threshold of energy density after which further increases in total energy consumption ceased. Moreover, there were no significant interactions between energy density and feeding frequency. In other words, greater energy intakes occurred with each added meal regardless of the energy density of the diet, and these intakes increased with each higher level of energy density for all meal frequencies.

The results indicate that the children were able to adjust their intakes to compensate in part for the different energy densities of the diets. Similar conclusions have been drawn from earlier studies of younger infants (Fomon et al. 1977), older pre-school children (Birch et al. 1989), and other recovering malnourished children (Sanchez-Griñan et al. 1992). Despite the children's apparent attempt to adjust intakes in response to differing energy density, their total energy intakes still varied according to energy concentration. At the lower densities it is likely that the children were physically unable to consume enough to satisfy their physiological needs because of limitations in gastric capacity, which has been estimated at 30-40 ml/kg body weight (Sanchez-Griñan et al. 1992). The intakes may have failed to reach a plateau at the higher densities either because the children had not satisfied their requirements for post-mainutrition compensatory growth, even with the highest-density diet, or because the adaptive decrease in intake with a high-density diet is not perfectly regulated.

\section{Effects of starch, simple sugar, and a non-energetic sweetener on total daily energy intake by young children}

Having examined the roles of energy density and frequency of feeding on young children's total daily energy intake, we next wanted to assess the possible role of macronutrient profiles. Complementary foods in many low-income settings are frequently composed of gruels prepared from starchy cereals and tubers. By contrast, transitional diets in more affluent settings contain more refined carbohydrates (CHO) and higher levels of fat. We, therefore, examined whether these differences in dietary components may influence energy intakes by young children.

To assess whether dietary starch content affects total daily energy intake, we offered three different porridges composed of rice, milk, vegetable oil and sugar $(3.1 \mathrm{~kJ} / \mathrm{g} \mathrm{diet}) \mathrm{ad}$ libitum four times daily for $3 \mathrm{~d}$ each to seventeen recovering malnourished children from 11 to 20 months of age (Brown et al. 1994). All diets contained $56 \%$ of energy as CHO, had similar viscosities, and were supplemented with a vitamin-mineral mix. The high- 
starch diet (diet ST) contained $83 \%$ of CHO energy as starch and $17 \%$ as sugar, and the high-sugar diet (diet SU) contained $67 \%$ of CHO energy as starch and $33 \%$ as sugar. Diet ST/SA was the same as diet ST except that saccharin was added to match the sweetness of diet SU. Mean energy intakes from diet ST (647 (SD 167) $\mathrm{kJ} / \mathrm{kg}$ body weight per d) and diet $\mathrm{SU}$ (642 (SD 171) kJ/kg body weight per d) were similar within child, but energy intakes from diet ST/SA (713 (SD 146) $\mathrm{kJ} / \mathrm{kg}$ body weight per d) were significantly greater $(P=0.007)$. We concluded that the starch content of a high-starch diet did not affect children's energy intake compared with an isoenergetic high-sugar, low-starch diet of similar viscosity. Increased intake of the saccharin-containing diet was apparently due to factors other than sweetness.

\section{Effects of varied dietary fat and carbohydrate concentrations on total daily energy intake by young children}

To assess whether variations in dietary fat and CHO contents affect total daily energy intake by young children, we studied eighteen children from 7 to 23 months of age, who were recovering in hospital from previous severe malnutrition. We offered each child two different porridges composed of rice, milk, vegetable oil and sugar $(5.0 \mathrm{~kJ} / \mathrm{g} \mathrm{diet}) \mathrm{ad}$ libitum four times daily for $4 \mathrm{~d}$ each. Both diets contained $11 \%$ energy as protein, and vitamin-mineral supplements were offered daily. The high-fat diet (diet HF) contained $45 \%$ of energy as fat and $44 \%$ as CHO; the low-fat diet (diet LF) contained $17 \%$ of energy as fat and $72 \%$ of energy as CHO. The diets had similar mean viscosities, and flavour and colour were as similar as possible (although not indistinguishable). Mean energy intakes from diet $\mathrm{HF}$ (713 (SD 159) kJ/kg body weight per d) were significantly greater than those from diet LF (647 (SD 142) kJ/kg body weight per d, $P<0.0001$ ). There were no differences in duration of meals, weight gain, or number of daily bowel movements by type of diet. We conclude that increasing the fat content of a mixed diet produced greater energy intake compared with an isoenergetic low-fat diet of similar viscosity, possibly because of differences in the palatability of the two preparations.

\section{Effects of varied or monotonous diets on total daily energy intake by young children}

Because of the limited range of foods available in many developing countries, complementary feeding regimens may be rather monotonous. It has been postulated that monotony of the diet in developing countries may explain to some degree the low levels of energy consumption that have been observed (Underwood, 1985). This hypothesis was examined in a recently completed clinical study in Peru (K. H. Brown, unpublished results). Children were offered either a single mixture of rice, milk, vegetable oil, and sugar during each of four meals daily for four consecutive days, as in the previously mentioned studies. During a second diet period they received four different preparations with similar nutrient content, but varied taste, colour, and consistency. Preliminary results indicate that the children consumed nearly $10 \%$ more when they received the varied dietary regimen. These findings are compatible with recent research results concerning sensory-specific satiety in adolescents and adults (Rolls \& McDermott, 1991). Thus, increasing the variety of the diet may be another means of enhancing total dietary intake.

\section{Effects of dietary viscosity on total daily energy intake by young children}

Special attention has been devoted recently to the issue of viscosity of transitional foods. This is due largely to increasing recognition of the influence of energy density on total 
energy intake and the fact that starch-containing staple foods are often extremely viscous when prepared at a sufficient concentration to assure adequate energy density. Possible means of augmenting energy density are to add fats or non-gelatinous $\mathrm{CHO}$, such as simple sugars, to the diet. However, each of these approaches implies the addition of 'empty calories' without accompanying protein or micronutrients. Thus, it is extremely important that the entire nutrient profile of the final mixed diet be analysed before issuing a blanket recommendation on the advisability of adding sugar or oil to complementary foods.

Several alternative methods have been described to reduce the viscosity of cereal mixtures, such as the addition of amylase (Gopaldas et al. 1986; Svanberg et al. 1987), fermentation (Alnwick et al. 1988), and extrusion cooking (Hellström et al. 1981). Of these, amylase has the greatest and most dramatic ability to reduce viscosity of a cereal porridge rapidly. Use of this enzyme is particularly attractive because it can be produced at the household level in developing countries by germinating local grains and producing malt flour, which is rich in amylase. However the impact of viscosity reduction on total energy intake is still being debated. Whereas some investigators have reported a positive impact of adding amylase or malt flour to children's diets on their total energy intake (Gopaldas et al. 1986, 1988; Gopaldas \& John, 1992; Rahman et al. 1994; Mitra et al. 1995), others have not (Lukmanji et al. 1989; Mosha \& Svanberg, 1990; Marquis et al. 1993; Stephenson et al. 1994). A recent review of this topic sponsored by the World Health Organization concluded that amylase (or malt)-treated diets failed to produce a consistently positive impact on children's total energy intakes (Ashworth \& Draper, 1992), although one more recent report noted that the time required for meals was reduced when a low-viscosity preparation replaced one of thicker consistency (Stephenson et al. 1994).

A number of uncertainties have been expressed regarding the safety of this technology (Alnwick et al. 1988; Ashworth \& Draper, 1992). Possible risks include the increased likelihood of microbial contamination of foods inoculated with home-produced malt flours after cooking, elevated osmolality of treated foods (Wahed et al. 1994), and cyanide toxicity from improperly-processed germinated grains. Because of the uncertain benefit of amylase-treated foods and the possible previously mentioned risks, there does not presently seem to be sufficiently compelling evidence to warrant extensive promotion of this technique, except under controlled conditions.

\section{CONCLUSIONS}

Energy consumption by young children in developing countries during the period of complementary feeding appears to be less than current international recommendations. Possible reasons include high rates of infection, which interfere with appetite; poor-quality diets; and suboptimal caregiver feeding behaviours. Efforts to enhance young children's dietary intake during this critical period for children's growth and development should include: (1) prevention and appropriate treatment of infections, (2) improvements in dietary quality to assure minimally adequate energy density, nutrient content, palatability, and diversity, (3) instruction of caregivers in appropriate frequency of feeding, encouragement and assistance of the child, and supervision of feeding episodes.

\section{REFERENCES}

Allen, L. H. (1994). Nutritional influences on linear growth: a general review. European Journal of Clinical Nutrition 48, Suppl. 1, S75-S89.

Alnwick, D., Moses, S. \& Schmidt, O. G. (editors) (1988). Improving Young Child Feeding in Eastern and Southern Africa. Household-Level Food Technology, IDRC-265e. Ottawa: International Development Research Centre. 
Ashworth, A. \& Draper, A. (1992). The Potential of Traditional Technologies for Increasing the Energy Density of Weaning Foods. WHO/CDD/EDP/92.4. Geneva: WHO.

Bentley, M. E., Black, M. M. \& Hurtado, E. (1995). Child-feeding and appetite: what can programmes do? Food and Nutrition Bulletin 16, 340-348.

Birch, L. L., McPhee, L. \& Sullivan, S. (1989). Children's food intake following drinks sweetened with sucrose or aspartame: time course effects. Physiological Behavior 45, 387-395.

Brown, K. H., Black, R. E., Becker, S. Nahar, S. \& Sawyer, J. (1982). Consumption of foods and nutrients by weanlings in rural Bangladesh. American Journal of Clinical Nutrition 36, 878-889.

Brown, K. H., Black, R. E., Lopez de Romaña, G. \& Creed de Kanashiro, H. (1989). Infant feeding practices and their relationship with diarrheal and other diseases. Pediatrics 83, 31-40.

Brown, K. H., Black, R. E., Robertson, A. D. \& Becker, S. (1985). Effects of season and illness on the dietary intake of weanlings during longitudinal studies in rural Bangladesh. American Journal of Clinical Nutrition 41, 343-355.

Brown, K. H., Peerson, J. M., Lopez de Romaña, G., Creed de Kanashiro, H. \& Black, R. E. (1995a). Validity and epidemiology of reported poor appetite among Peruvian infants from a low-income, periurban community. American Journal of Clinical Nutrition 61, 26-32.

Brown, K. H. \& Perez, F. (1992). Determinants of dietary intake during childhood diarrhoea and implications for appropriate nutritional therapy. Acta Paediatrica 381, Suppl., 127-132.

Brown, K. H., Sanchez-Griñan, M. I., Perez, F., Peerson, J. M., Ganoza, L. \& Stern, J. S. (1995b). Effects of dietary energy density and feeding frequency on total daily energy intakes by recovering malnourished children. American Journal of Clinical Nutrition 62, 13-18.

Brown, K. H., Sanchez-Griñan, M. I., Perez, F., Peerson, J. M. \& Stern, J. S. (1994). Effect of dietary starch and sugar contents on total daily energy intakes by recovering malnourished children. FASEB Journal 8, A155.

Brown, K. H., Stallings, R. Y., Creed de Kanashiro, H., Lopez de Romaña, G. \& Black, R. E. (1990). Effects of common illnesses on infants' energy intakes from breast milk and other foods during longitudinal communitybased studies in Huascar (Lima), Peru. American Journal of Clinical Nutrition 52, 1005-1013.

Butte, N. F. (1996). Energy requirements of infants. European Journal of Clinical Nutrition 50, Suppl., S24 S36.

Cohen, R. J., Brown, K. H., Canahuati, J., Rivera, L. L. \& Dewey, K. G. (1994). Effects of age of introduction of complementary foods on infant breast milk intake, total energy intake, and growth: a randomised intervention study in Honduras. Lancet 344, 288-293.

Creed de Kanashiro, H., Brown, K. H., Lopez de Romaña, G., Lopez, T. \& Black, R. E. (1990). Consumption of food and nutrients by infants in Huascar (Lima), Peru. American Journal of Clinical Nutrition 52, $995-1004$.

Dettwyler, K. A. (1989). Styles of infant feeding: parental/caretaker control of food consumption in young children. American Anthropology 91, 696-703.

De Zoysa, I., Rea, M. \& Martines, J. (1991). Why promote breast-feeding in diarrhoeal disease control programmes? Health Policy \& Planning 6, 371-379.

Dickin, K. L., Brown, K. H., Fagbule, D., Adedoyin, M., Gittelsohn, J., Esrey, S. A. \& Oni, G. A. (1990). Effect of diarrhoea on dietary intake by infants and young children in rural villages of Kwara State, Nigeria. European Journal of Clinical Nutrition 44, 307-317.

Drewett, R., Amatayakul, K., Wongsawasdii, L., Mangklabruks, A., Ruckpaopunt, S., Ruangyuttikarn, C., Baum, D., Imong, S., Jackson, D. \& Woolridge, M. (1993). Nursing frequency and the energy intake from breast milk and supplementary food in a rural Thai population: a longitudinal study. European Journal of Clinical Nutrition 47, 880-891.

Engle, P. L. \& Ricciuti, H. M. (1995). Psychosocial aspects of care and nutrition. Food and Nutrition Bulletin 16, 356-377.

Fomon, S. J., Filer, L. J. Jr, Ziegler, E. E., Bergmann, K. E. \& Bergmann, R. L. (1977). Skim milk in infant feeding. Acta Paediatrica Scandinavica 66, 17 -30.

Gopaldas, T. \& John, C. (1992). 1. Evaluation of a controlled 6 months feeding trial on intake by infants and toddlers fed a high energy-low bulk gruel versus a high energy-high bulk gruel in addition to their habitual home diet. Journal of Tropical Pediatrics 38, 278-283.

Gopaldas, T., Deshpande, S. \& John, C. (1988). Studies on a wheat-based amylase-rich food. Food and Nutrition Bulletin 10, 55-59.

Gopaldas, T., Mehta, P., Patil, A. \& Gandhi, H. (1986). Studies on reduction in viscosity of thick rice gruels with small quantities of an amylase-rich cereal malt. Food and Nutrition Bulletin 8, 42-47.

Hellström, A., Hermansson, A. M., Karlsson, A., Ljungqvist, B., Mellander, O. \& Svanberg, U. (1981). Dietary bulk as a limiting factor for nutrient intake - with special reference to the feeding of pre-school children. II. Consistency as related to dietary bulk - a model study. Joumal of Tropical Pediatrics 27, 127-135.

Hoyle, B., Yunus, M. \& Chen, L. C. (1980). Breast-feeding and food intake among children with acute diarrheal disease. American Journal of Clinical Nutrition 33, 2365-2371.

John, C. \& Gopaldas, T. (1993). II. Evaluation of the impact on growth of a controlled 6-month feeding trial on children (6-24 months) fed a complementary feed of a high energy-low bulk gruel versus a high energy-high bulk gruel in addition to their habitual home diet. Journal of Tropical Pediatrics 39, 16-22. 
Lukmanji, Z., Ljungqvist, B., Hedqvist, F. \& Elisonguo, C. (1988). Child feeding patterns in Tanzania with reference to feeding frequency and dietary bulk. In Improving Young Child Feeding in Eastern and Southern Africa. IDRC-265e, pp. 300-311 [D. Alnwick, S. Moses and O. G. Schmidt, editors]. Ottawa: International Development Research Centre.

Marquis, G. S., Lopez, T., Peerson, J. M. \& Brown, K. H. (1993). Effect of dietary viscosity on energy intake by breast-fed and non-breast-fed children during and after acute diarrhea. American Journal of Clinical Nutrition 57, $218-223$.

Martorell, R., Yarbrough, C., Yarbrough, S. \& Klein, R. E. (1980). The impact of ordinary illnesses on the dietary intake of malnourished children. American Journal of Clinical Nutrition 33, 345-350.

Mata, L. (1978). The Children of Santa Maria Cauque. Cambridge, MA: MIT Press.

Mata, L. J., Kromal, R. A., Urrutia, J. J. \& Garcia, B. (1977). Effect of infection on food intake and the nutritional status: perspectives as viewed from the village. American Journal of Clinical Nutrition 30, 12151227.

Mitra, A. K., Rahman, M. M., Mahalanabis, D., Patra, F. C. \& Wahed, M. A. (1995). Evaluation of an energydense meal liquefied with amylase of germinated wheat in children with acute watery diarrhoea: a randomized controlled clinical trial. Nutrition Research 15, 939-951.

Molla, A. M., Molla, A., Sarker, S. A. \& Rahaman, M. M. (1983). Food intake during and after recovery of diarrhea in children. In Diarrhea and Malnutrition, pp. 113-123 [L. C. Chen and N. S. Scrimshaw, editors]. New York: Plenum Press.

Mosha, A. C. \& Svanberg, U. (1990). The acceptance and intake of bulk-reduced weaning foods: the Luganga village study. Food and Nutrition Bulletin 12, 69-74.

Popkin, B. M., Adair, L., Akin, J. S., Black, R., Briscoe, J. \& Flieger, W. (1990). Breast-feeding and diarrheal morbidity. Pediatrics 86, 874-882.

Rahman, M. M., Islan, M. A., Mahalanabis, D., Biswas, E., Majid, N. \& Wahed, M. A. (1994). Intake from an energy-dense porridge liquefied by amylase of germinated wheat: a controlled trial in severely malnourished children during convalescence from diarrhoea. European Journal of Clinical Nutrition 48, 45-53.

Rolls, B. J. \& McDermott, T. M. (1991). Effects of age on sensory-specific satiety. American Joumal of Clinical Nutrition 54, 988-996.

Sanchez-Grinan, M. I., Peerson, J. M. \& Brown, K. H. (1992). Effect of dietary energy density on total adlibitum energy consumption by recovering malnourished children. European Journal of Clinical Nutrition 46, 197-204.

Sarker, S. A., Molla, A. M., Karma, A. K. M. M. \& Rahaman, M. M. (1982). Calorie intake in childhood diarrhoea. Nutrition Reports International 26, 581-590.

Stephenson, D. M., Meeks Gardner, J. M., Walker, S. P. \& Ashworth, A. (1994). Weaning-food viscosity and energy density: their effects on ad libitum consumption and energy intakes in Jamaican children. American Joumal of Clinical Nutrition 60, 465-469.

Svanberg, U. S.-O., Fredrikzon, B., Gebre-Hiwot, B. \& Taddesse, W. W. (1987). Sorghum in a mixed diet for preschool children. I. Good acceptability with and without simple reduction of dietary bulk. Journal of Tropical Pediatrics 33, 181-185.

Torun, B., Davies, P. S. W., Livingstone, M. B. E., Paolisso, M., Sackett, R. \& Spurr, G. B. (1996). Energy requirements and dietary energy recommendations for children and adolescents 1 to 18 years old. European Journal of Clinical Nutrition 50, Suppl., S37-S81.

Underwood, B. A. (1985). Weaning practices in deprived environments: the weaning dilemma. Pediatrics 75, Suppl., 194-198.

Van Steenbergen, W. M., Kusin, J. A., Kardjati, S. \& Renqvist, U. H. (1991). Nutritional transition during infancy in East Java, Indonesia: A longitudinal study of feeding pattern, breast milk intake, and the consumption of additional foods. European Journal of Clinical Nutrition 45, 67-75.

Van Steenbergen, W. M., Kusin, J. A., Vorrhoeve, A. M. \& Jansen, A. A. J. (1980). Measured food intake of preschool children in Machakos district. East African Medical Journal 57, 735-744.

Wahed, M. A., Mahalanabis, D., Begum, M., Rahman, M. \& Islam, M. S. (1994). Energy-dense weaning foods liquefied by germinated-wheat amylase: effects on viscosity, osmolality, macronutrients, and bacterial growth. Food and Nutrition Bulletin 15, 257-261.

Waterlow, J. C. (editor) (1988). Observations on the natural history of stunting. In Linear Growth Retardation in Less Developed Countries. Nutrition Workshop Series, vol. 14, pp. 1-16. New York: Nestec Lid, Vevey/ Raven Press Ltd.

World Health Organization (1985). Energy and Protein Requirements. Report of a Joint FAO/WHO/UNU Expert Consultation. Technical Report Series no. 724. Geneva: WHO. 